\title{
Penerapan Model Pembelajaran Cooperative Learning Tipe Jigsaw dalam Meningkatkan Hasil Belajar Siswa Pokok Bahasan Menatap Masa Depan dengan Optimis, Ikhtiar dan Tawakal Kelas $\mathrm{IX}_{\mathrm{E}}$ SMPN 2 Kota Bima Tahun Pelajaran 2019/2020
}

\author{
Faridah \\ ${ }^{1}$ Sekolah Menegah Pertama Negeri 02 Kota Bima Nusa Tenggara Barat \\ Email: Faridahsmp02.66@gmail.com
}

\begin{abstract}
ABSTRAK
Tujuan penelitian ini adalah untuk menerapkan Model Pembelajaran Cooperative Learning Tipe Jigsaw II dalam meningkatan hasil belajar siswa dengan pokok bahasan Menatap masa depan dengan optimis, ikhtiar

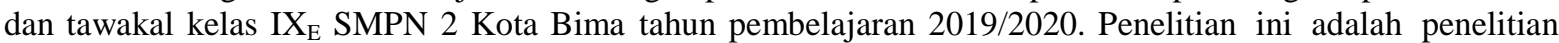
tindakan kelas ( P T K) Classroom action research yang dilaksanakan dengan empat (4) tahapan dalam tiap siklus yang meliputi perencanaan, pelaksanaan, observasi/evaluasi dan refleksi. Adapun yang menjadi subyek penelitian adalah siswa kelas $\mathrm{IX}_{\mathrm{E}}$ SMPN 2 Kota Bima dengan jumlah siswa sebanyak 28 siswa terdiri dari 11 laki-laki dan 17 perempuan. Adapun yang menjadi tolok ukur keberhasilan adalah apabila hasil belajar siswa kelas $\mathrm{IX}_{\mathrm{E}}$ mampu mencapai nilai $\mathrm{KKM}$ yaitu $\geq 65$, dan banyak siswa yang tuntas belajar (Ketuntasan Klasikal) minimal 85\% dengan nilai rata-rata kelas minimal 70,0 dan keaktifan siswa minimal mencapai $70 \%$. Hasil penelitian didapat pada siklus I siswa yang tuntas belajar klasikal ada 21 siswa ( $67,86 \%$ ) dengan nilai rata- rata kelas 76,92 dan persentase keaktifan siswa mencapai $79 \%$ sedangkan pada siklus II siswa yang tuntas belajar klasikal ada 25 siswa ( 89,29\% ) dengan nilai rata- rata kelas 80,77 dan persentase keaktifan siswa mencapai $86 \%$, Karena sudah memenuhi indikator keberhasilan yang diharapkan, maka proses penelitian berakhir pada siklus II.
\end{abstract}

\section{Kata Kunci : Cooperative Learning Tipe Jigsaw II, Hasil Belajar}

\begin{abstract}
The purpose of this study was to determine the application of improved student learning outcomes by applying and to find out the Jigsaw II Type Cooperative Learning Model improve student learning outcomes subject matter Looking up to the future with optimism, endeavor and trust in class IXE SMPN 2 Bima City 2019/2020 learning year. This research is a classroom action research. Classroom action research is carried out with four (4) stages in each cycle which include planning, implementation, observation / evaluation and reflection. As for the subjects of the study were students of IXE grade at SMPN 2 Bima City with 28 students consisting of 11 men and 16 women. As for the benchmarks of success is if the IXE grade student learning outcomes are able to achieve the KKM value of $\geq 65$, and many students who have completed learning (Classical Completeness) of at least $85 \%$ with an average grade of at least 70.0 and student activity of at least $70 \%$. The results obtained in the first cycle of students who completed classical learning there were 21 students $(67.86 \%)$ with an average grade of 76.92 and the percentage of student activity reached $79 \%$ while in the second cycle students who completed classical learning there were 25 students $(89,29 \%)$ with an average grade of 80.77 and the percentage of student activity reaching $86 \%$, because it has met the indicators of expected success, the research process ends in the second cycle.
\end{abstract}

Keywords: Cooperative Learning Type Jigsaw II, Learning Outcomes

\section{PENDAHULUAN}

Adanya masalah siswa kurang termotivasi dalam mempelajari pendidikan Agama Islam dan Budi Pekerti, selain itu masalah tersebut juga menyebabkan pendidikan Agama Islam an Budi Pekerti di sekolah kurang memberikan sumbangan yang berarti bagi pendidikan anak secara keseluruhan, baik pengembangan kemampuan berpikir, bagi pembentukan sikap maupun pengembangan kepribadian secara keseluruhan pendidikan 
Agama Islam Dan Budi Pekerti sangat berguna bagi diri siswa. Dalam bidang pengembangan kepribadian, pendidikan Agama Islam dan Budi Pekerti di sekolah masih belum mampu mengambil peran mengenai apa yang paling baik bagi dirinya, demokratis, bersifat jujur dan berani bertanggung jawab terhadap segala hal yang menyangkut tanggungjawab pribadi siswa untuk menatap masa depan, sesuai hasil observasi awal pada kelas VIII SMPN 2 Kota Bima tahun pelajaran 2018/2019 masih ada beberapa kelas yg belum tuntas, masih dibawah nilai rata-rata ketuntasan.

Dengan situasi seperti itu pendidikan Agama Islam dan Budi Pekerti di sekolah dan pendidikan formal pada umumnya, cenderung menghasilkan lulusan yang mempunyai banyak pengetahuan, tetapi miskin dalam kemampuan berpikir dan miskin dalam hal kepribadian, termasuk berjiwa penakut, kurang berani mengambil keputusan dan kurang berani bertanggungjawab atas perbuatan yang telah dilakukan.

Pembelajaran pendidikan Agama Islam dan Budi Pekerti di sekolah bertujuan untuk mengacu kepada fungsi pendidikan Agama Islam dan Budi Pekerti serta kepada tujuan pendidikan nasional yang telah dirumuskan dalam Garis-garis Besar Halauan Negara (GBHN). Diungkapkan dalam Garis-garis Besar Program Pengajaran (GBPP), bahwa tujuan utama diberikannya pendidikan Agama Islam dan Budi Pekerti pada jenjang pendidikan dasar dan menengah, untuk mempersiapkan siswa agar sanggup menghadapi perubahan keadaan didalam kehidupan dunia yang selalu berkembang, melalui latihan bertindak atas dasar pemikiran secara logis, rasional, kritis, cermat, jujur, efektif dan efisien mempersiapkan siswa agar dapat menggunakan pendidikan Agama Islam dan Budi Pekerti dan pola pikir pendidikan Agama Islam dan Budi Pekerti dalam kehidupan sehari-hari dan dalam mempelajari berbagai ilmu pengetahuan, kondisi yang di harapkan agar prestasi belajar siswa meningkat, guru harus dapat menciptakan suasana yang dapat merangsang siswa, agar aktif dan senang mengikuti proses belajar mengajar. Guru harus memiliki kemampuan untuk memiliki model pembelajaran yang tepat dalam proses belajar mengajar. Model pembelajaran yang dapat mengaktifkan siswa belajar sesuai dengan materi yang diajarkan.

Berdasarkan data dari hasil observasi kelas VIII di SMPN 2 Kota Bima tahun pelajaran 2018/2019 menunjukkan, masih ada beberapa kelas yang mengalami penurunan nilai rata-rata maupun hasil belajar kalas $\mathrm{IX}_{\mathrm{E}}$ mengalami kesulitan dalam menyelesaikan soal-soal menatap masa depan dengan optimis, ikhtiar dan tawakal. Kesulitan yang dialami 
siswa dalam menyelesaikan soal yang memuat menatap masa depan dengan optimis, ikhtiar dan tawakal disebabkan karena siswa kurang mampu dalam memahami soal tersebut.

Hal ini dapat dibuktikan dengan rendahnya hasil belajar siswa, baik dilihat dari nilai hasil tes formatif maupun tes sumatif, rata-rata nilai sumatif kelas $\mathrm{IX}_{\mathrm{E}}$ SMPN 2 Kota Bima tahun 2018/2019 semester Ganjil menunjukkan nilai rata-rata hanya mencapai 57,0 dan semester II nilai rata-ratanya sedikit meningkat 59,0. Rata-rata yang diperoleh lebih rendah jika dibanding rata-rata nilai mata pelajaran Pendidikan Agama Islam Budi Pekerti di kelas lain sedangkan untuk nilai dalam penyelesaian soal-soal menatap masa depan dengan optimis, ikhtiar dan tawakal tidak terlalu rendah rata-rata 66,0 dan siswa yang tuntas belajar $69 \%$. Sedangkan persentase keaktifan siswa hanya mencapai $72 \%$. Oleh karena itu selanjutnya diharapkan bahwa dengan pengalaman guru melalui implementasi model pembelajaran Cooperative Learning Tipe Jigsaw II hasil belajar dan keaktifan siswa dapat ditingkatkan.

Berdasarkan uraian di atas mendorong penulis untuk mengadakan penelitian tentang bagaimanakah cara meningkatkan hasil belajar siswa dalam menyelesaikan soal menatap masa depan dengan optimis, ikhtiar dan tawakal melalui implementasi model pembelajaran Cooperative Learning Tipe Jigsaw II bagi siswa kelas IX $_{\mathrm{E}}$ SMPN 2 Kota Bima tahun pembelajaran 2019/2020.

\section{METODE PENELITIAN}

Penelitian ini merupakan penelitian tindakan kelas (PTK). Pemilihan jenis penelitian ini didasari bahwa PTK merupakan penelitian tindakan yang paling tepat dipahami, dikuasai dan dilaksanakan oleh guru dalam tugas meningkatkan mutu proses pembelajaran adalah PTK Supardui dan Suharjono, 2011).

Penelitian ini dilaksanakan di SMPN 2 Kota Bima pada semester ganjil tahun pelajaran 2019/2020. Subyek penelitian adalah peserta didik kelas $\mathrm{IX}_{\mathrm{E}}$ yang berjumlah 28 orang.

Pelaksanaan penelitian ini dilaksanakan menggunakan siklus, hal ini didasarkan pada ketuntasan hasil belajar siswa dengan jadwal pelajaran sesuai dengan jadwal yang berlaku di sekolah Kelas IX E SMPN 2 Kota Bima, tahun pelajaran 2019/2020 semester ganjil. Tiap siklus dilaksanakan dengan 3 (tiga) kali pertemuan dan begitu pula siklus selanjutnya. Materi/pokok bahasan yang diambil dalam penelitian ini adalah menatap 
masa depan dengan optimis, ikhtiar dan tawakal, dengan pembagian sub pokok bahasan dalam tiap pertemuan.

Penelitian ini dilaksanakan dalam 4 tahapan, yaitu (1) perencanaan, (2) pelaksanaan tindakan, (3) observasi/evaluasi, dan (4) refleksi. Sumber data penelitian diperoleh dari peserta didik dan guru, dengan jenis data berupa data kualitatif (data aktivitas peserta didik dan guru) dan kuantitatif (data hasil belajar peserta didik). Data aktivitas guru dan peserta didik diambil dengan teknik observasi dengan menggunakan lembar observasi pada tiap pertemuan. Sedangkan data hasil belajar peserta didik dari setiap siklus diperoleh dengan memberikan tes berbentuk pilihan ganda sebanyak 10 butir dan essay 5 butir.

Data aktivitas peserta didik dianalisis secara deskriptif kualitatif dengan menggunakan $\mathrm{M}_{\mathrm{i}}$ (mean ideal) dan $\mathrm{SD}_{\mathrm{i}}$ (standar deviasi ideal) dengan skor 0 dan 1. Jumlah yang diamati sebanyak 5 indikator dengan skor masing-masing indikator adalah 3. Maka skor maksimal yang diperoleh siswa adalah 15 dan skor minimal yamg mungkin adalah dan 0 . Berikut uraian analisis data aktivitas belajar siswa menggunakan $\mathrm{M}_{\mathrm{i}}$ (mean ideal) dan $\mathrm{SD}_{\mathrm{i}}$ (standar deviasi ideal) dengan rumus:

$\mathrm{MI}=\frac{1}{2}($ skor tertinggi + skor terendah $)=\frac{1}{2}(4+1)=2,5$

$\mathrm{SDI}=\frac{1}{6}($ skor tertinggi - skor terendah $)=\frac{1}{6}(4-1)=0,5$

Keterangan :

MI

: Mean Ideal

SDI : Standar Definisi Ideal

Berdasarkan skor standar, maka kriteria untuk menentukan aktivitas belajar siswa dijabarkan pada tabel berikut:

\section{Tabel 1: Pedoman Kriteria Aktivitas Siswa}

\begin{tabular}{|c|c|c|}
\hline Interval & Nilai & Kategori \\
\hline $\mathrm{M}_{\mathrm{i}}+1,5 \mathrm{SD}_{\mathrm{i}}<\mathrm{X}<\mathrm{M}_{\mathrm{i}}+3 \mathrm{SD}_{\mathrm{i}}$ & $11,25 \leq X<15$ & Sangat aktif \\
\hline $\mathrm{Mi}_{\mathrm{i}}+0,5 \mathrm{SD}_{\mathrm{i}} \leq \mathrm{X}<\mathrm{Mi}_{\mathrm{i}}+1,5 \mathrm{SD}_{\mathrm{i}}$ & $8,75 \leq X<11,25$ & Aktif \\
\hline $\mathrm{Mi}_{\mathrm{i}}-0.5 \mathrm{SD} \mathrm{i}<\mathrm{X}<\mathrm{Mi}_{\mathrm{i}}+0.5 \mathrm{SD}$ & $6.25<X<8.75$ & Cukup aktif \\
\hline $\mathrm{M}_{\mathrm{i}}-1,5 \mathrm{SD}_{\mathrm{i}} \leq \mathrm{X}<\mathrm{M}_{\mathrm{i}}-0,5 \mathrm{SD}_{\mathrm{i}}$ & $3,75 \leq X<6,25$ & Kurang aktif \\
\hline $\mathrm{M}_{\mathrm{i}}-3 \mathrm{SD}_{\mathrm{i}} \leq \mathrm{X}<\mathrm{M}_{\mathrm{i}}-1,5 \mathrm{SD}_{\mathrm{i}}$ & $0 \leq X<3,75$ & Sangat kurang aktif \\
\hline
\end{tabular}

(Sumber: Diadaptasi dari Nurkencana dan Sunarta, 2001)

Indikator perilaku peserta didik yang diamati, yaitu (1) antusiasme peserta didik dalam kegiatan pembelajaran, (2) interaksi peserta didik dengan guru, (3) aktivitas peserta 
didik mencari dan memberi informasi materi, (4) aktivitas peserta didik dalam diskusi kelompok, dan (5) partisipasi peserta didik dalam merangkum/menyimpulkan materi.

Sementara data aktivitas guru diperoleh melalui pengamatan langsung oleh observer (guru teman sejawat) ketika guru mengajar di kelas dengan menggunakan lembar observasi berupa activity check list. Adapun indikator perilaku guru yang diamati dalam penelitian ini adalah (1) melakukan apersepsi dan memotivasi peserta didik, (2) mengamati kegiatan peserta didik, (3) memberi petunjuk atau membimbing kegiatan peserta didik, (4) kemampuan menciptakan suasana kelas yang kondusif, dan (5) melibatkan peserta didik dalam merangkum/ menyimpulkan materi. Aktivitas guru minimal berkategori "baik", dengan mengacu pada Instrumen Penilaian Pelaksanaan Pembelajaran Dinas Pendidikan dan Kebudayaan Kota Bima.

Adapun data hasil belajar peserta didik diketahui dari hasil tes setelah dianalisis secara deskriptif, yaitu dengan menentukan nilai rata-rata tes hasil. Analisis untuk mengetahui tes hasil belajar dirumuskan sebagai betikut:

$\bar{X}=\frac{\sum X}{\sum N}$

Keterangan: $\bar{X}=$ Nilai rata-rata

$\Sigma \mathrm{X}=$ Jumlah semua nilai siswa

$\Sigma \mathrm{N}=$ Jumlah siswa

(Diadaptasi Sudjono dan Anas, 2010)

Untuk ketuntasan belajar ada dua kategori, yaitu ketuntasan individu dan ketuntasan klasikal. Seorang siswa dikatakan telah tuntas belajar (individu) apabila telah mencapai skor minimal ketuntasan belajar (KKM) yaitu $\geq 70$ yang telah ditetapkan di SMPN 2 Kota Bima pada seluruh mata pelajaran. Untuk ketuntasan belajar klasikal apabila di kelas tersebut terdapat $85 \%$ yang telah mencapai ketuntasan belajar dari jumlah siswa seluruhnya (Trianto, 2010).

Selanjutnya, indikator keberhasilan penelitian ini adalah (1) aktivitas peserta didik minimal berkategori Aktif dan mengalami peningkatan rata-rata skor pada tiap siklusnya. Begitu juga aktivitas guru dalam pembelajaran minimal berkategori baik, (2) Hasil 
belajar peserta didik dikatakan meningkat apabila rata-rata kelas mengalami peningkatan dari siklus ke siklus berikutnya, dan (3) tercapainya ketuntasan belajar secara Klasikal pada peserta didik.

\section{HASIL DAN PEMBAHASAN}

Penelitian tindakan kelas ini dilaksanakan dengan tujuan untuk meningkatkan aktivitas peserta didik dan hasil belajar peserta didik kelas $\mathrm{IX}_{\mathrm{E}}$ pada pokok bahasan menatap masa depan dengan optimis, ikhtiar dan tawakal. Penelitian ini dilaksanakan menggunakan siklus. Tiap siklus dilaksanakan dalam 3 (tiga) pertemuan.

Hasil penelitian pada siklus I menunjukkan bahwa aktivitas belajar peserta didik termasuk kategori aktif dengan rata-rata skor aktivitas belajar peserta didik sebesar 2,6. Hal ini diketahui dari aktivitas belajar siswa selama proses pembelajaran, bahwa antusiasme siswa dalam mengikuti pembelajaran, aktivitas mencari atau memberi informasi dan interaksi dengan anggota kelompok dilakukan dengan aktif. Pembelajaran cooperative learning mengacu pada model pembeajaran di mana siswa bekerja bersama dalam kelompok kecil saling membantu dalam belajar. Banyak terdapat pendekatan kooperatif yang berbeda antara satu dengan yang lainnya. Kebanyakan melibatkan siswa dalam kelompok yang terdiri dari empat siswa dengan kemampuan yang berbeda-beda (Slaum, 1994) dan yang lain menggunakan ukuran kelompok yang berbeda-beda (Cohen,1986 : Johnson \& Johnson, 1994 : Kagan, 1992 : Sharan \& Sharan, 1992) khas pembelajaran kooperatif, siswa di tempatkan pada kelompok-kelompok untuk beberapa minggu, mereka biasanya dilatih keterampilan-keterampilan spesifik untuk membantu mereka bekerja sama dengan baik, memberikan penjelasan dengan baik, mengajukan pertanyaan dengan benar dan sebagainya.

Aktivitas pembelajaran kooperatif dapat memainkan banyak peran dalam pelajaran. Dalam satu pelajaran tertentu pembelajaran kooperatif dapat digunakan untuk tujuan yang berbeda, sebagai misal dalam satu pelajaran tertentu para siswa bekerja sebagai kelompok-kelompok yang sedang berupaya mengemukakan sesuatu (misalnya saling membantu mengungkapkan bagaimana keadaan air di dalam botol, dapat mengatakan juga kepada mereka tentang prinsip-prinsip suara). Setelah pelajaran yang resmi terjadwal itu habis, siswa dapat bekerja sebagai kelompok-kelompok diskusi. Akhirnya, siswa mendapat kesempatan bekerja sama untuk memastikan bahwa seluruh anggota kelompok telah menguasai segala sesuatu tentang pelajaran tersebut dalam persiapan untuk 
kuis, bekerja dalam suatu format belajar kelompok. Di dalam skenario yang lain, kelompok kooperatif dapat digunakan untuk memecahkan sebuah masalah kompleks.

Selanjutnya, untuk hasil belajar peserta didik diperoleh ketuntasan sebesar 67,86\% dan rata-rata kelas sebesar 76,92. Presentase ketuntasan ini berarti masih belum melampaui batas presentase ketuntasan minimal sebesar 85\%. Oleh karena demikian masih dilanjutkan pada siklus II, karena masih terdapat beberapa kekurangan selama pelaksanaan pembelajaran. Argumentasi lain untuk dilanjutkan pada siklus II adalah bahwa penelitian tindakan kelas paling sedikit atau tidak kurang dari 2 (dua) siklus (Supardi dan Suhardjono, 2011).

Sebagaimana dipaparkan di atas bahwa aktivitas selama proses pembelajaran, seperti antusiasme siswa dalam mengikuti pembelajaran, keaktifan mencari atau memberi informasi, dan proses`interaksi siswa berjalan dengan baik, dapat berdampak pada meningkatnya hasil belajar (kompetensi kognitif) siswa. Hal ini dipahami juga sebagai dampak diterapkannya Model Pembelajaran Cooperative Learning Tipe Jigsaw II yang men-setting peserta didik berinteraksi dengan sangat aktif selama berlangsungnya pembelajaran. Pemilihan metode atau model pembelajaran yang tepat bagi siswa dalam suatu pembelajaran, menurut Muhibbin (2003) dapat mempengaruhi hasil belajar siswa, yang dikenal dengan faktor pendekatan belajar (approach to learning), di samping faktor internal dan eksternal peserta didik.

Sementara kekurangan pada siklus I terjadi karena beberapa peserta didik belum menguasai materi, sehingga kurang lancar dalam mentransfer materi kepada peserta didik lain. Hal lain, sejumlah peserta didik merasakan sedikitnya waktu yang diberikan dalam menerima informasi materi dari peserta didik lain ketika mengunjungi kelompoknya, sehingga penguasaan materi tidak mudah dicapai. Kemudian sebagian peserta didik lebih fokus pada kegiatan mencatat ketika menerima informasi dari peserta didik lain, padahal seharusnya lebih mendahulukan pemahaman materi. Dipaparkan pula di sini bahwa peserta didik masih malu (kurang percaya diri) menanyakan hal-hal yang belum dipahaminya.

Kemudian proses pembelajaran siklus II dilaksanakan seperti pembelajaran siklus I, tetapi guru melakukan perbaikan-perbaikan berdasarkan kekurangan-kekurangan yang ditemukan pada siklus I. Berdasarkan hasil observasi aktivitas belajar peserta didik pada siklus II diperoleh rata-rata skor aktivitas belajar peserta didik mengalamai peningkatan dari siklus I, yaitu dari 76,92 dengan kategori aktif meningkat menjadi 80,77 dengan 
kategori sangat aktif. Hal ini terjadi karena pada siklus II peserta didik mengikuti semua tahapan pembelajaran dengan menerapkan Model Pembelajaran Cooperative Learning Tipe Jigsaw II sangat aktif dan berusaha memperbaiki kekurangan-kekurangan yang muncul selama tindakan pada siklus sebelumnya.

Dari hasil evaluasi siklus II diperoleh nilai ketuntasan belajar peserta didik meningkat dari ketuntasan belajar siklus I, yaitu 67,86\% (21 orang) meningkat menjadi 89,29\% (25 orang). Sementara untuk rata-rata kelas pada siklus II juga mengalami peningkatan dari siklus I, yaitu 76,92 meningkat menjadi 80,77.

Secara keseluruhan hasil dari penelitian ini menunjukkan bahwa penerapan Model Pembelajaran Cooperative Learning Tipe Jigsaw II dapat meningkatkan aktivitas dan hasil belajar peserta didik pada pokok bahasan menatap masa depan dengan optimis, ikhtiar dan tawakal. Hal ini disebabkan dalam penerapan Model Pembelajaran Cooperative Learning Tipe Jigsaw II, peserta didik sendiri belajar melalui partisifasi aktif untuk meningkatkan aktivitas belajarnya dan untuk meningkatkan hasil belajarnya.

Jadi, dapat disimpulkan bahwa penerapan Model Pembelajaran Cooperative Learning Tipe Jigsaw II dalam pembelajaran Pendidikan Agama Islam dan Budi Pekerti dapat menjadikan peserta didik semakin aktif dalam belajar, baik secara individu maupun kelompok, sehingga berdampak meningkatnya hasil atau prestasi belajar peserta didik. Karena sebagaimana diketahui bahwa selama penelitian, penerapan Model Pembelajaran Cooperative Learning Tipe Jigsaw II ini dapat membuat peserta didik lebih aktif selama berlangsungnya pembelajaran, karena peserta didik beraktivitas layaknya di pasar. Melakukan aktivitas jual beli informasi. Terdapat peserta didik atau kelompok peserta didik pemilik informasi untuk "dijual" (disampaikan) pada peserta didik atau kelompok lain sebagai yang "membeli" (menerima) informasi yang dapat diterapkan di sekolah.

\section{KESIMPULAN}

Penerapan Model Pembelajaran Cooperative Learning Tipe Jigsaw II dapat meningkatkan aktivitas belajar Pendidikan Agama Islam dan Budi Pekerti. Hal ini terlihat dari adanya peningkatan rata-rata skor aktivitas belajar peserta didik dari siklus I $(76,92)$ dengan kategori aktif ke siklus II $(80,77)$ dengan kategori sangat aktif. Demikian juga dengan model pembelajaran ini dapat meningkatkan hasil belajar Pendidikan Agama Islam dan Budi Pekerti. Hal ini terlihat dari ketuntasan belajar peserta didik mengalami 
peningkatan dari siklus I sebesar 67,86\% ke siklus II sebesar 89,29\%. Demikian juga ratarata kelas mengalami peningkatan dari siklus I sebesar 76,92 ke siklus II sebesar 80,77. Peningkatan aktivitas dan hasil belajar peserta didik dari satu siklus ke siklus berikutnya sebagai dampak diterapkannya Model Pembelajaran Cooperative Learning Tipe Jigsaw II, yang merupakan pembelajaran berbasis active learning.

\section{DAFTAR PUSTAKA}

Depdikbud. 1988. Kamus Besar Bahasa Indonesia. Jakarta : Balai Pustaka. Depdiknas. 2004. Materi pelatihan Terintegrasi Buku 3.

Slavin, Robert,E. 1995. Cooperative Learning: Theory, Research and Practice. Second Edition. Boston : Allyn and Bacon Publisher.

Johnson, DW dan Johnson, RT. 1994. Learning together and alone: Cooperative, cooperative, and individualistic learning (4 th ed.). Boston: Allyn dan Bacon.

Arikunto. 2006. Prosedur Penelitian Suatu Pendekatan Praktik. Jakarta : PT. Rineka Cipta.

Aunurrahman. 2009. Belajar dan Pembelajaran. Bandung : Alfabeta.

Kunandar. 2008. Penelitian Tindakan Kelas : Sebagai Pengembangan Profesi Guru. Jakarta :

PT. Grafindo Persada.

Ridwan. 2009. Metode dan Teknik Menyusun Proposal Penelitian. Bandung : Alfabeta.

Sagala. 2007. Konsep dan Makna Pembelajaran. Bandung : CV. Alfabeta.

Sugiyono. 2009. Metode Penelitian Kuantitatif, Kualitatif dan $R \& B$. Bandung : Alfabeta.

Suharsimi, Arikunto, Suhardjono, Supardi. 2010. Penelitian Tindakan Kelas. Jakarta : Bumi Aksara.

Slameto. 2003. Belajar Dan Faktor-Faktor Yang Mempengaruhinya. Jakarta: Rineka Cipta.

Zainal. 2002. Profesionalisme Guru dalam Pembelajaran. Surabaya : Insan Cendekia.

Agus Suprijono. (2015). Cooperative Learning Teori \& Aplikasi Paikem. Yogyakarta : Pustaka Pelajar.

Dirman \& Juarsih, Cicih. (2014). Penilaian dan Evaluasi dalam Rangka Implementasi Standar Proses Pendidikan Siswa. Jakarta : PT. Rineka Cipta.

Dimyati \& Mudjiono. (2013). Belajar dan Pembelajaran. Jakarta : PT. Rineka Cipta.

Dwi Siswoyo, dkk. (2008) . Ilmu Pendidikan. Yogyakarta : UNY Press.

Imam Ghozali. (2011). Aplikasi Analisis Multivariate dengan Program IBM SPSS 19.

Semarang : Badan Penerbit Universitas Diponegoro. 
Miftahul Huda. (2015). Cooperative Learning Metode, Teknik, Struktur dan Model Terapan. Yogyakarta : Pustaka Belajar.

Nana Sudjana. (2014). Penilaian Hasil Proses Belajar Mengajar. Bandung : PT. Remaja Rosdakarya.

Ridwan Abdullah Sani. (2014). Pembelajaran Saintifik untuk Implementasi Kurikulum 2013. Jakarta : PT. Bumi Aksara.

Ridwan Abdullah Sani. (2016). Penilaian Autentik. Jakarta : PT. Bumi Aksara.

Sugiyono. (2015). Metode Penelitian Pendidikan Pendekatan Kuantitatif, Kualitatif, dan $R \& D$. Bandung : Alfabeta.

Tawardjono Usman, dkk. (2014). Peningkatan Mutu Pembelajaran Teknologi Pengecatan melalui Metode Jigsaw Bagi Mahasiswa Otomotif FT UNY. Jurnal JPTK. UNY. (Online: http://journal.uny.ac.id/index.php/jptk, diakses 28 Maret 2017).

Permendikbud Nomor 81A Tahun 2013, Implementasi Kurikulum, Lampiran IV. Pedoman Umum Pembelajaran:Jakarta.

Permendikbud Nomor 65 Tahun 2013 tentang Standar Proses Pendidikan dasar dan Menengah.

Permendikbud Nomor 70 Tahun 2013 tentang Kerangka Dasar dan Struktur

Kurikulum Sekolah Menengah Kejuruan/ Madrasah Aliyah Kejuruan. Permen Diknas Nomor 19 Tahun 2005 tentang Proses Pembelajaran Pendidikan.

Undang-undang Republik Indonesia no. 20 Tahun 2003 tentang Sistem Pendidikan Indonesia. 